ORIGINAL ARTICLE

\title{
Impact of ambient air pollution on birth weight in Sydney, Australia
}

\author{
T Mannes, B Jalaludin, G Morgan, D Lincoln, V Sheppeard, S Corbett
}

Occup Environ Med 2005;62:524-530. doi: 10.1136/oem.2004.014282

See end of article for authors' affiliations

.....................

Correspondence to: Ms T F Mannes, NSW Public Health Officer Training Program, New South Wales Health Department, LMB 961 North Sydney, Australia; paman@doh.health.nsw. gov.au

Accepted 24 February 2005

\begin{abstract}
Background: Studies in Asia, Europe, and the Americas have provided evidence that ambient air pollution may have an adverse effect on birth weight, although results are not consistent.

Methods: Average exposure during pregnancy to five common air pollutants was estimated for births in metropolitan Sydney between 1998 and 2000. The effects of pollutant exposure in the first, second, and third trimesters of pregnancy on risk of "small for gestational age" (SGA), and of pollutant exposure during pregnancy on birth weight were examined.

Results: There were 138056 singleton births in Sydney between 1998 and 2000; 9.7\% of babies (13 402) were classified as SGA. Air pollution levels in Sydney were found to be quite low. In linear regression models carbon monoxide and nitrogen dioxide concentrations in the second and third trimesters had a statistically significant adverse effect on birth weight. For a 1 part per million increase in mean carbon monoxide levels a reduction of $7(95 \% \mathrm{Cl}-5$ to 19$)$ to $29(95 \% \mathrm{Cl} 7$ to 51$)$ grams in birth weight was estimated. For a 1 part per billion increase in mean nitrogen dioxide levels a reduction of 1 (95\% Cl 0 to 2) to 34 (95\% Cl 24 to 43 ) grams in birth weight was estimated. Particulate matter (diameter less than ten microns) in the second trimester had a small statistically significant adverse effect on birth weight. For a 1 microgram per cubic metre increase in mean particulate matter levels a reduction of 4 grams (95\% $\mathrm{Cl} 3$ to 6) in birth weight was estimated.

Conclusion: These findings of an association between carbon monoxide, nitrogen dioxide, and particulate matter, and reduction in birth weight should be corroborated by further study.
\end{abstract}

$\mathrm{E}$ pidemiological studies addressing the relation between ambient air pollution and fetal development are accumulating worldwide. Studies conducted in China, ${ }^{1}$ the Czech Republic, ${ }^{2}{ }^{3}$ Korea, ${ }^{4}$ the UK, ${ }^{5}$ Brazil, ${ }^{6}$ and North America $^{7-11}$ have examined the link between ambient air pollution levels during pregnancy and reduction in birth weight or intrauterine growth retardation (IUGR). There is evidence to suggest that air pollutant exposure during pregnancy has an adverse impact on birth weight, although the findings are inconsistent; the effect of individual pollutants and the period(s) during pregnancy when pollutant levels are likely to have most impact on birth weight is not clear.

It is useful, then, to examine the impact of ambient air pollution and birth weight in a variety of different sites to clarify the nature of the relation. We examined this relation in Sydney as there is complete, routinely collected data available. In the present study we evaluated the effect of prenatal exposure (in early, mid, and late pregnancy) to five common urban air pollutants: particulate matter $\left(\mathrm{PM}_{10}\right.$ and $\left.\mathrm{PM}_{2.5}\right)$, carbon monoxide (CO), nitrogen dioxide $\left(\mathrm{NO}_{2}\right)$, and ozone $\left(\mathrm{O}_{3}\right)$ from routine air monitoring in the Sydney metropolitan area on birth weight.

\section{METHODS}

Information on all births in metropolitan Sydney between 1 January 1998 and 31 December 2000 was obtained from the Midwives Data Collection (MDC) at the New South Wales Department of Health. The MDC is a population based surveillance system covering all live births and stillbirths of at least 20 weeks gestation and at least 400 grams birth weight. Birth data includes maternal demographic factors (age, smoking status, country of birth, postcode of residence at time of delivery), pregnancy factors (date of the last menstrual period, gestational hypertension and diabetes, parity, time of first antenatal visit to a healthcare provider), details about the delivery (type of delivery), and infant factors (birth weight, gestational age). Other known causes of low birth weight including multiple births, hypertension of pregnancy, and gestational diabetes were excluded.

We obtained daily air pollution data from the New South Wales Environment Protection Authority (EPA) and daily meteorological data from the Australian Bureau of Meteorology. Air pollution data included concentrations of $\mathrm{PM}_{10}, \mathrm{PM}_{2.5}, \mathrm{NO}_{2}, \mathrm{O}_{3}$, and $\mathrm{CO}$ recorded at 14 monitoring stations in metropolitan Sydney. Monitoring stations were excluded if less than $80 \%$ of readings were available for each pollutant. Pollutant concentrations were analysed as continuous variables.

For each birth, exposure to each air pollutant during gestation was estimated by calculating the average of each pollutant over 30 days (last month) and 90 days (third trimester) before birth, the mid 90 days of gestation (second trimester), and 90 days (first trimester) after the estimated date of conception. Pollutant concentrations from monitoring stations were averaged to provide an estimate for the whole of metropolitan Sydney, using an approach similar to the APHEA2 (Short-term Effects of Air Pollution and Health: A European Approach) studies. ${ }^{12-14}$ The process was repeated

Abbreviations: ABS, Australian Bureau of Statistics; APHEA, Short-term Effects of Air Pollution and Health: A European Approach; $\mathrm{Cl}$, confidence interval; EPA, Environment Protection Authority; IRSD, Index of Relative Socioeconomic Disadvantage; IUGR, intrauterine growth retardation; LBW, low birth weight; LMP, last menstrual period; MDC, midwives data collection; NSW, New South Wales; $\mathrm{PM}_{2.5}$, particulate matter less than 2.5 microns diameter; $\mathrm{PM}_{10}$, particulate matter less than 10 microns diameter; ppb, parts per billion $\left(10^{-9}\right)$; ppm, parts per million $\left(10^{-6}\right)$; SD, standard deviation; $\mathrm{SE}$, standard error; SES, socioeconomic status; $S G A$, small for gestational age; $O R$, odds ratio; Temp, temperature; TSP, total suspended particulates 


\begin{tabular}{|c|c|c|c|c|c|}
\hline \multirow[b]{2}{*}{ Variable } & \multicolumn{2}{|c|}{$\begin{array}{l}\text { Small for gestational age } \\
(n=13402)\end{array}$} & \multicolumn{2}{|c|}{$\begin{array}{l}\text { Not small for gestational age } \\
(n=138056)\end{array}$} & \multirow[b]{2}{*}{ Adjusted OR $(95 \% \mathrm{Cl})$} \\
\hline & No. & $\%$ & No. & $\%$ & \\
\hline \multicolumn{6}{|l|}{ Maternal age (years) } \\
\hline$<24$ & 2762 & 20.6 & 19460 & 14.1 & $1.02(0.97$ to 1.08$)$ \\
\hline $25-34^{*}$ & 8340 & 62.2 & 93828 & 68.0 & 1.00 \\
\hline $35-44$ & 2285 & 17.0 & 24639 & 17.8 & $1.01(0.95$ to 1.01$)$ \\
\hline$>45$ & 15 & 0.1 & 129 & 0.1 & 1.55 (0.84 to 2.84$)$ \\
\hline \multicolumn{6}{|l|}{ Maternal smoker } \\
\hline Yes & 2659 & 19.8 & 14254 & 10.3 & 1.97 (1.87 to 2.08$)$ \\
\hline No & 10741 & 80.1 & 110375 & 79.9 & \\
\hline \multicolumn{6}{|l|}{ Sex of infant } \\
\hline Female & 6456 & 48.2 & 60381 & 43.7 & $1.01(0.97$ to 1.05$)$ \\
\hline Male & 6946 & 51.8 & 64273 & 46.6 & \\
\hline Maternal Aboriginality & & 0.0 & & 0.0 & \\
\hline Yes & 117 & 0.9 & 806 & 0.6 & $1.03(0.83$ to 1.28$)$ \\
\hline No & 13275 & 99.1 & 123758 & 89.6 & \\
\hline \multicolumn{6}{|l|}{ Gestation at first antenatal visit } \\
\hline$>20$ weeks & 1803 & 13.5 & 13854 & 10.0 & 1.12 (1.05 to 1.18$)$ \\
\hline$\leqslant 20$ weeks & 11486 & 85.7 & 110014 & 79.7 & \\
\hline \multicolumn{6}{|l|}{ Previous pregnancy } \\
\hline No & 7427 & 55.4 & 53102 & 38.5 & $0.57(0.54$ to 0.59$)$ \\
\hline Yes & 5973 & 44.6 & 71517 & 51.8 & \\
\hline \multicolumn{6}{|l|}{ IRSD quintile } \\
\hline 5 (least disadvantaged; high SES)* & 3843 & 28.7 & 58638 & 42.5 & 1.00 \\
\hline 4 & 2857 & 21.3 & 27395 & 19.8 & 1.24 (1.17 to 1.13$)$ \\
\hline 3 & 2374 & 17.7 & 19997 & 14.5 & $1.38(1.30$ to 1.46$)$ \\
\hline 2 & 1684 & 12.6 & 13826 & 10.0 & $1.50(1.41$ to 1.61$)$ \\
\hline 1 (most disadvantaged; low SES) & 2644 & 19.7 & 18200 & 13.2 & 1.73 (1.63 to 1.83 ) \\
\hline \multicolumn{6}{|l|}{ Season of birth } \\
\hline Summer (Dec-Feb)* & 3265 & 24.4 & 43727 & 31.7 & 1.00 \\
\hline Autumn (Mar-May) & 3456 & 25.8 & 31109 & 22.5 & 1.05 (0.99 to 1.11$)$ \\
\hline Winter (Jun-Aug) & 3375 & 25.2 & 31469 & 22.8 & $1.00(0.95$ to 1.06$)$ \\
\hline Spring (Sep-Nov) & 3306 & 24.7 & 31751 & 23.0 & $0.99(0.94$ to 1.05$)$ \\
\hline
\end{tabular}

*Referent group.

$\mathrm{OR}$, odds ratio adjusted for other covariates; SD, standard deviation; SES, socioeconomic status.

Note that in Australia, autumn is in March, April, May; winter is in June, July, August; spring is in September, October, November; and summer is in December, January, February.

matching air pollution concentrations from each eligible monitoring station and births to mothers residing in postcodes within $5 \mathrm{~km}$ of the monitoring station.

The following covariates were included in regression models: sex of child, maternal age (in year groupings), gestational age (only included in linear regression models), maternal smoking (yes/no), gestational age at first antenatal visit ( $\leqslant 20$ weeks or $>20$ weeks), maternal indigenous status (whether mother identifies as being Aboriginal or Torres Strait Islander), whether first pregnancy, season of birth, and socioeconomic status (SES). SES was measured using the Index of Relative Socioeconomic Disadvantage (IRSD) of postcode of maternal residence. The Australian Bureau of Statistics (ABS) constructs the IRSD to classify geographical areas on the basis of social and economic information collected in the population census. Each postcode in New South Wales (population of approximately 1000-5000 people) is assigned an IRSD index. We then ranked the postcodes and divided the list into quintiles.

A variable "small for gestational age" (SGA) was calculated based on the Australian national birth weight centile for gestational age 1991-94. ${ }^{15}$ SGA was defined as greater than two standard deviations below the mean birth weight according to gestational age as SGA. SGA was analysed as a categorical variable in logistic regression models using the SAS System for Windows v8.02. Linear regression models were also developed using birth weight as a continuous variable. Following the development of the basic model, air pollutants were then added to the model to determine the association between ambient air pollutants and birth weight. Single and multi-pollutant pollutant models were assessed and we investigated interactions between air pollution variables and covariates. The impact of pollutant exposures in other pregnancy periods on key findings was also analysed.

\section{RESULTS}

There were 138056 singleton births in Sydney between 1998 and 2000; $9.7 \%$ of babies ( 13 402) were classified as SGA. Mean (SD) birth weight for babies born in Sydney between 1998 and 2000 was 3418 (531) grams. After adjusting for other maternal and infant characteristics, SGA was significantly associated with maternal smoking, gestational age greater than 20 weeks at first antenatal visit, and first pregnancy (table 1). All SES variables exhibit a statistically significant association with SGA. Compared to the high SES category, there was increasing risk of SGA with decreasing SES.

Pollutant concentrations in Sydney from 1 April 1997 to 31 December 2000 are presented in table 2. A correlation matrix of air pollution variables is presented in table 3 to show correlations between pollutants. Correlation coefficients above 0.8 were observed between $\mathrm{PM}_{10}$ and $\mathrm{PM}_{2.5}$. Correlation coefficients were also calculated to determine the correlations between air monitoring stations. Correlation coefficients between the 14 monitoring stations ranged from 0.68 to 0.85 for $\mathrm{CO}$. Correlation coefficients between the 14 monitoring stations ranged from 0.46 to 0.85 for $\mathrm{NO}_{2}$; from 0.53 to 0.94 for $\mathrm{O}_{3}$; from 0.67 to 0.91 for $\mathrm{PM}_{10}$; and from 0.66 to 0.93 for $\mathrm{PM}_{2.5}$. All pollutants differed according to season $(\mathrm{p}<0.01)$ and post hoc analysis revealed that all seasons were different to all others $(\mathrm{p}<0.05)$. Concentrations of $\mathrm{CO}$, $\mathrm{NO}_{2}$, and $\mathrm{PM}_{2.5}$ were highest in winter and lowest in summer. Concentrations of $\mathrm{PM}_{10}$ and $\mathrm{O}_{3}$ were highest in summer and lowest in winter. 
Table 2 Daily average pollutant concentrations for air monitoring stations in Sydney, 1 April 1997-31 December 2000

\begin{tabular}{|c|c|c|c|c|c|c|c|}
\hline & $\begin{array}{l}\text { Australian National } \\
\text { Standard }\end{array}$ & Mean (SD) & Minimum & 25th centile & Median & 75th centile & Maximum \\
\hline \multicolumn{8}{|l|}{$\begin{array}{l}\text { Pollutant } \\
\text { PM }_{10}\left(\mu \mathrm{g} / \mathrm{m}^{3}\right)\end{array}$} \\
\hline $\begin{array}{c}24 \text { hour av } \\
\mathrm{PM}_{2.5}\left(\mu \mathrm{g} / \mathrm{m}^{3}\right)\end{array}$ & $50 \mu \mathrm{g} / \mathrm{m}^{3}$ & $16.8(7.1)$ & 3.8 & 12.3 & 15.7 & 19.9 & 104.0 \\
\hline $\begin{array}{l}24 \text { hour av } \\
\text { CO (ppm) }\end{array}$ & $25 \mu \mathrm{g} / \mathrm{m}^{3 *}$ & $9.4(5.1)$ & 2.4 & 6.5 & 8.4 & 11.2 & 82.1 \\
\hline $\begin{array}{l}8 \text { hour av } \\
\mathrm{O}_{3} \text { (ppb) }\end{array}$ & 9.0 ppm & $0.8(0.7)$ & 0.0 & 0.4 & 0.6 & 1.1 & 4.6 \\
\hline $\begin{array}{l}1 \text { hour max } \\
\mathrm{NO}_{2}(\mathrm{ppb})\end{array}$ & 100 ppb & $31.6(14.6)$ & 3.2 & 22.7 & 27.7 & 36.3 & 126.7 \\
\hline 1 hour max & 120 ppb & $23.2(7.4)$ & 56.2 & 18.0 & 23.0 & 27.5 & 59.4 \\
\hline
\end{tabular}

Citywide average air pollutant concentrations in the last month, third trimester, and first trimester of pregnancy had no statistically significant effect on SGA after adjusting for infant and maternal characteristics (table 4). Concentrations of $\mathrm{PM}_{10}, \mathrm{PM}_{2.5}$, and $\mathrm{O}_{3}$ in the second trimester of pregnancy had a small but statistically significant adverse effect on SGA (OR 1.01, 95\% CI 1.00 to 1.04 ; OR $1.03,95 \%$ CI 1.01 to 1.05 ; and OR 1.01, 95\% CI 1.00 to 1.01 , respectively).

Eleven metropolitan air monitoring stations were eligible for inclusion in the analysis of babies born to women residing within $5 \mathrm{~km}$ of an air monitoring station (table 4). There were 51460 eligible births in 1998-2000. Of these, 5985 $(11.6 \%)$ were classified as SGA. $\mathrm{NO}_{2}$ concentrations in the second and third trimesters and one month before birth had a statistically significant adverse effect on risk of SGA (ORs between 1.07 and 1.14) (table 4). The $\mathrm{NO}_{2}$ effects were robust to controlling for exposures in other pregnancy periods (ORs between 1.1 (95\% CI 1.0 to 1.2 ) and 1.1 (95\% CI 1.0 to 1.2) for second and third trimesters respectively). Exposure to $\mathrm{PM}_{10}$ in the second trimester of pregnancy had a small but statistically significant adverse effect on risk of SGA (OR $1.02,95 \%$ CI 1.01 to 1.03 ) (table 4), although these findings were not robust to analysis when controlling for exposures to $\mathrm{PM}_{10}$ in other periods of pregnancy (OR 1.01, 95\% CI 0.99 to $1.02)$.

In multivariate linear regression models, the effect of pollutant concentrations on birth weight (in grams) was examined for all births in Sydney during the study period and for babies born to women residing within $5 \mathrm{~km}$ of an air monitoring station (table 5). Citywide average levels of $\mathrm{PM}_{10}$ and $\mathrm{PM}_{2.5}$ in the second trimester and last month of pregnancy had a small but statistically significant adverse effect on birth weight. When analysing only babies born to women residing within $5 \mathrm{~km}$ of an air monitoring station, we observed a small adverse effect of $\mathrm{PM}_{10}$ exposure during the second trimester on birth weight (regression coefficient -4.3 , $95 \%$ CI -5.8 to -2.8 ). Thus, for every $1 \mu \mathrm{g} / \mathrm{m}^{3}$ increase in 24 hour average $\mathrm{PM}_{10}$ during the second trimester of pregnancy, a 4 gram reduction in birth weight was estimated. This finding persisted after controlling for exposures in other pregnancy periods and analysis in multi-pollutant models (table 6).

Citywide average levels of $\mathrm{CO}$ in the last month of pregnancy had a statistically significant adverse effect on birth weight, whereas the $5 \mathrm{~km}$ results reveal an adverse effect of $\mathrm{CO}$ exposure on birth weight for the second and third trimesters of pregnancy. Linear regression coefficients for the $5 \mathrm{~km}$ analysis ranged from -23 (95\% CI -44.6 to $-1.2)$ to $-29(95 \%$ CI -51.0 to -6.8$)$; thus, for every 1 part per million increase in 8 hour average CO during pregnancy, a 23-29 gram reduction in birth weight was estimated. Analysis of second trimester CO findings in two and three pollutant models and controlling for exposures in other pregnancy periods are presented in table 6. CO findings in the second trimester did not remain statistically significant when analysed in multi-pollutant models.

Citywide average levels of $\mathrm{NO}_{2}$ in the first and third trimesters of pregnancy resulted in a small but statistically significant adverse effect on birth weight, whereas the $5 \mathrm{~km}$ results reveal an adverse effect of $\mathrm{NO}_{2}$ exposure on birth weight for all periods of pregnancy. Linear regression coefficients for the $5 \mathrm{~km}$ analysis ranged from -20 (95\% CI -27.8 to -11.5$)$ to $-34(95 \%$ CI -43.4 to -24.3$)$. $\mathrm{NO}_{2}$ findings in the second trimester remained when analysed in two pollutant models, but did not remain when analysed in the four pollutant model (table 6).

Table 3 Matrix of Pearson correlation coefficients of pollutant concentrations (averaged across all air monitoring stations) in Sydney, April 1997-December 2000, and birth outcomes for term births in Sydney, 1998-2000

\begin{tabular}{llrrrrrr}
\hline Pollutant & Birth weight & \multicolumn{1}{c}{ CO } & NO $_{2}$ & O $_{3}$ & PM $_{10}$ & PM $_{2.5}$ & Temp \\
\hline Birth weight & 1.00 & 1.00 & & & & & \\
$\mathrm{CO}$ & 0.00 & 0.57 & 1.00 & & & & \\
$\mathrm{NO}_{2}$ & 0.01 & -0.20 & 0.29 & 1.00 & & & \\
$\mathrm{O}_{3}$ & 0.01 & 0.26 & 0.47 & 0.52 & 1.00 & & \\
$\mathrm{PM}_{10}$ & 0.01 & 0.53 & 0.66 & 0.36 & 0.81 & 1.00 & \\
$\mathrm{PM}_{2.5}$ & 0.01 & -0.42 & -0.16 & 0.60 & 0.38 & 0.05 & 1.00 \\
Temp & 0.00 & & & & & & \\
\hline
\end{tabular}

Temp, temperature; ppb, parts per billion $\left(10^{-9}\right)$; ppm, parts per million $\left(10^{-6}\right)$; $\mathrm{CO}$, carbon monoxide, 8 hour average in $\mathrm{ppm} ; \mathrm{O}_{3}$, ozone, 1 hour max in $\mathrm{ppb} ; \mathrm{PM}_{10}$, particulate matter less than 10 microns, 24 hour average in $\mu \mathrm{g} / \mathrm{m}^{3} ; \mathrm{PM}_{2.5}$, particulate matter less than 2.5 microns, 24 hour average in $\mu \mathrm{g} / \mathrm{m}^{3} ; \mathrm{NO}_{2}$, nitrogen dioxide, 24 hour average in $\mathrm{ppb}$. 


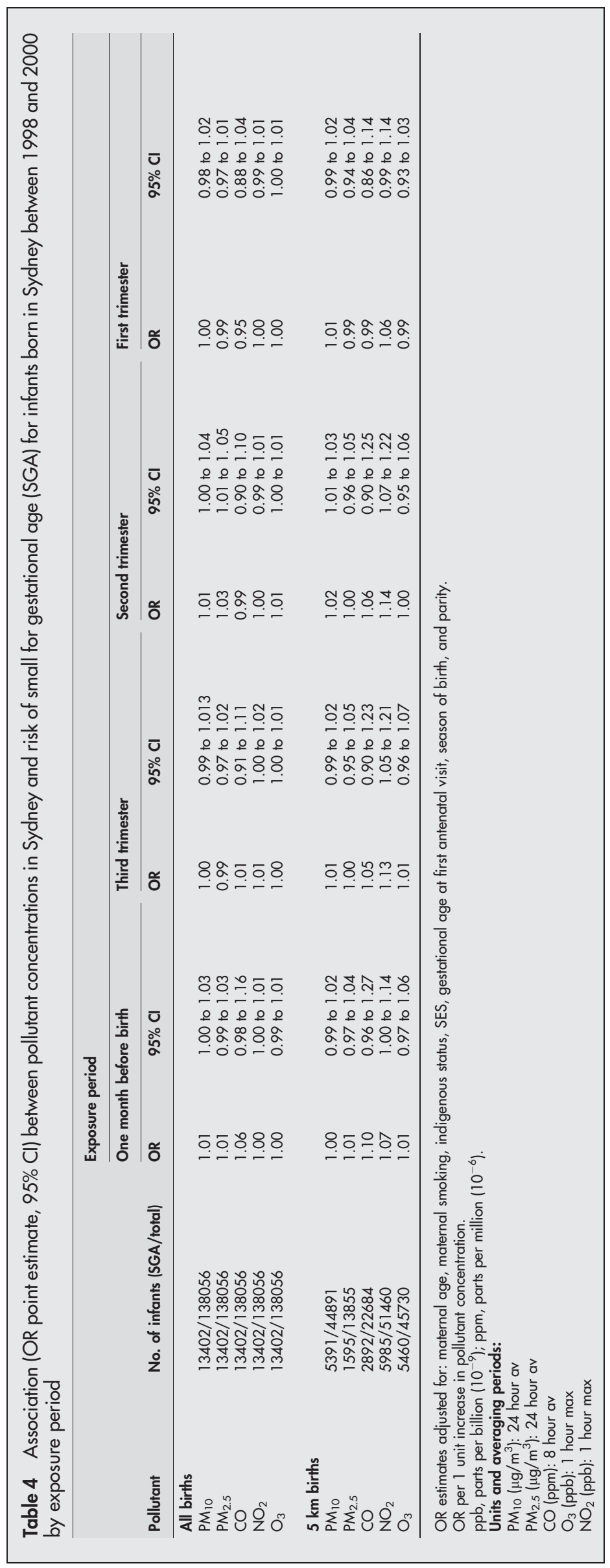

\section{DISCUSSION}

We examined associations between birth weight and exposure to air pollution concentrations at various stages of pregnancy across all of Sydney and for those infants born to women residing within $5 \mathrm{~km}$ of air monitoring stations. We showed a small effect of $\mathrm{PM}_{10}$ concentration in the second trimester of pregnancy, on birth weight in both linear and logistic regression models. We also showed that $\mathrm{CO}$ and $\mathrm{NO}_{2}$ concentrations in the second and third trimesters of pregnancy (most pronounced in the second trimester), had a statistically significant effect on birth weight. The effect of $\mathrm{NO}_{2}$ concentrations was only seen when examining births to women residing within $5 \mathrm{~km}$ of an air monitoring station. The effect of $\mathrm{CO}$ concentrations was only seen in the linear regression analysis and was most pronounced when examining births to women residing within $5 \mathrm{~km}$ of an air monitoring station.

There are a number of strengths to our study. We were able to investigate the association between low birth weight and pollutant concentrations for a large number of births in metropolitan Sydney between 1998 and 2000, and we were able to test this association using information on infants born to women residing within $5 \mathrm{~km}$ of an air monitoring station, again for a large number of births. We were also able to analyse the effect of five common air pollutants $\left(\mathrm{PM}_{10}, \mathrm{PM}_{2.5}, \mathrm{CO}, \mathrm{NO}_{2}\right.$, and $\left.\mathrm{O}_{3}\right)$, as these pollutants are routinely monitored at many air monitoring stations in metropolitan Sydney. One strength of this study is that we have been able to control for maternal smoking, indigenous status, gestational age at first antenatal visit, and parity among other potential confounders.

Although our analysis controlled for a number of important potential confounders, we did not have the information to adjust for some known risk factors for low birth weight; for example, maternal nutrition, maternal occupation, or pre-pregnancy maternal weight. Also, residual confounding by SES cannot be ruled out. Our SES estimate is a group level variable assigned to postcode of maternal residence at time of birth.

The most important source of bias in our study is due to measurement of exposure. By using air pollutant concentrations averaged across Sydney, we assume that ambient pollutant concentrations represent an individual's actual exposure to pollutants. This assumption does not account for timeactivity patterns that may mediate exposure such as commuting habits, place or type of work, or time spent outdoors.

The use of citywide average exposure does not account for variations in pollutant concentrations across Sydney or even within the $5 \mathrm{~km}$ zone around an air monitoring station. It is likely that pollutants, particularly primary pollutants such as nitrogen dioxide and carbon monoxide, are not homogeneously distributed across Sydney. The distribution of primary pollutants will largely depend on the presence of combustion sources such as roads or industry. Thus we also examined the impact of pollutant concentrations only for births to women residing within $5 \mathrm{~km}$ of an air monitoring station to attempt to provide a better estimate of exposure for pollutants with large geographic variability. Analysis of the effect of $\mathrm{CO}$ and $\mathrm{NO}_{2}$ shows a clear pattern of increased effect when examining only births to 


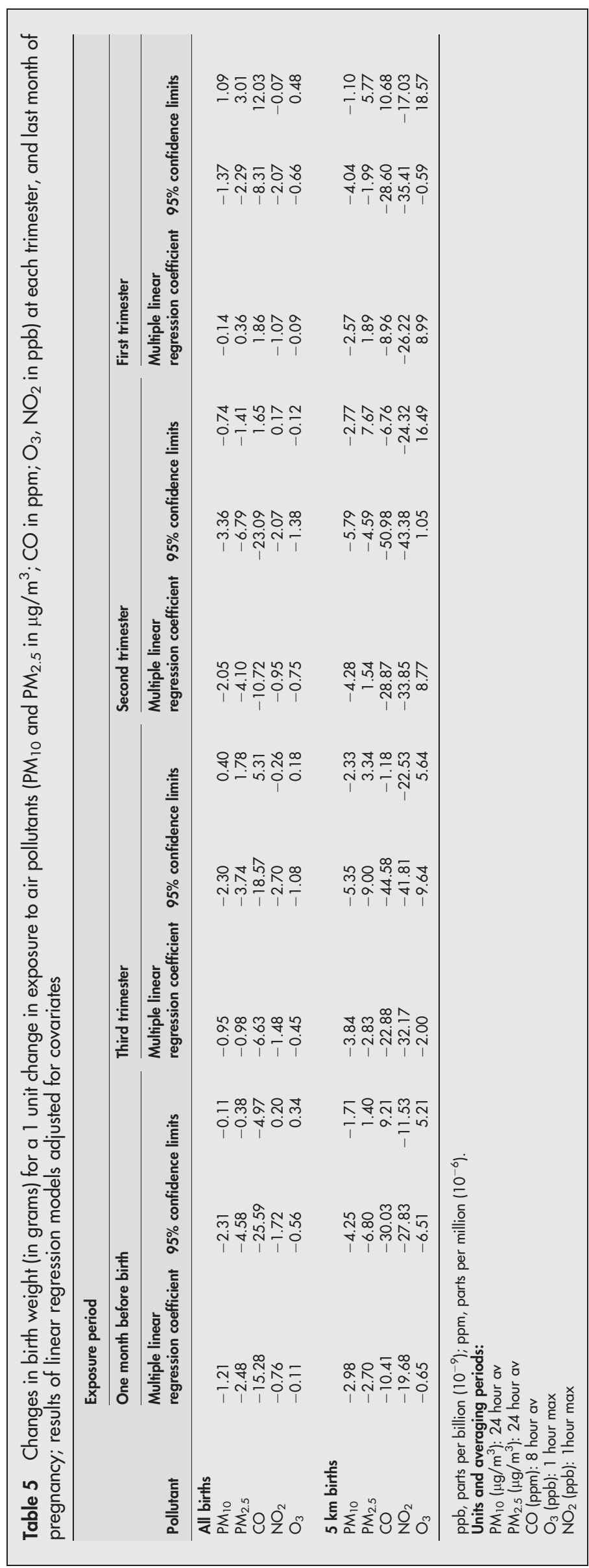

women residing within $5 \mathrm{~km}$ of an air monitoring station. Ozone and $\mathrm{PM}_{2.5}$ are secondary pollutants and thus should be more homogeneously distributed throughout metropolitan Sydney. The effects of concentrations of $\mathrm{PM}_{2.5}$ and $\mathrm{O}_{3}$ change little when analysing only births to women residing within $5 \mathrm{~km}$ of an air monitoring station.

Our findings of an adverse effect of particulates in the second trimester and of $\mathrm{NO}_{2}$ and $\mathrm{CO}$ at various stages of pregnancy on birth weight have been replicated in previous studies. In a meta-analysis of studies examining the impact of particulate exposure on birth weight, Glinianaia and colleagues ${ }^{16}$ concluded that in those studies where an effect of particulates in birth outcomes has been shown, there is considerable variability in the stage of pregnancy that the impact occurs. ${ }^{16}$ The same can be said of those studies examining the impact of other pollutants on birth weight.

Chen and colleagues ${ }^{9}$ examined the impact of ambient $\mathrm{PM}_{10}$ and other pollutant concentrations on birth weight in Northern Nevada (USA) between 1991 and 1999, and found that exposure to $\mathrm{PM}_{10}$ in the third trimester of pregnancy was negatively associated with birth weight in Nevada. ${ }^{9}$ Gouveia and colleagues ${ }^{6}$ examined the impact of $\mathrm{O}_{3}, \mathrm{CO}$, and $\mathrm{PM}_{10}$ concentrations on birth weight in Sao Paolo, Brazil in 1997, and found that first trimester exposure to $\mathrm{CO}$ and $\mathrm{PM}_{10}$ had an adverse affect on birth weight. No association between $\mathrm{O}_{3}$ concentrations in any trimester and birth weight was observed.

IUGR, defined as birth weight below the 10th centile of recorded birth weight, was associated with exposure to $\mathrm{PM}_{2.5}$ and $\mathrm{PM}_{10}$ concentrations in the first trimester of pregnancy in Northern Bohemia. ${ }^{3}$ In the Czech Republic, IUGR was not associated with exposure to sulphur dioxide $\left(\mathrm{SO}_{2}\right)$ and total suspended particulate (TSP) concentrations during pregnancy. ${ }^{2}$ Bobak ${ }^{2}$ also reported that exposure to $\mathrm{SO}_{2}$, TSP, and oxides of nitrogen $\left(\mathrm{NO}_{\mathrm{x}}\right)$ during pregnancy had no affect on risk of low birth weight, after adjusting for gestational age (as well as other maternal characteristics). Ha and colleagues ${ }^{4}$ examined the effect of exposure to $\mathrm{CO}, \mathrm{NO}_{2}$, TSP, and $\mathrm{SO}_{2}$ in the first trimester of pregnancy on low birth weight in Seoul, South Korea. For each inter-quartile increase in pollutant the relative risk of low birth weight was 1.08 for $\mathrm{CO}, 1.07$ for $\mathrm{NO}_{2}, 1.06$ for $\mathrm{SO}_{2}$, and 1.04 for TSPs. ${ }^{4}$ No effect of exposure to these pollutants in the third trimester of pregnancy was noted.

$\mathrm{Liu}$ and colleagues ${ }^{11}$ examined the effect of $\mathrm{SO}_{2}$, $\mathrm{NO}_{2}, \mathrm{CO}$, and $\mathrm{O}_{3}$ concentrations on IUGR, low birth weight, and preterm birth in Vancouver, Canada. Low birth weight was associated with exposure to $\mathrm{SO}_{2}$ during the first month of pregnancy (OR 1.1 for a $5 \mathrm{ppb}$ increase). IUGR was associated with exposure to $\mathrm{SO}_{2}$ (OR 1.1 for a $5 \mathrm{ppb}$ increase), $\mathrm{NO}_{2}$ (OR 1.1 for a $10 \mathrm{ppb}$ increase), and CO (OR 1.1 for a $1 \mathrm{ppm}$ increase) in the first month of pregnancy.

Last trimester exposure to CO in Los Angeles, USA was reported to result in an increased risk of low birth weight in term births after adjusting for maternal characteristics including commuting habits $(\mathrm{OR}=1.22){ }^{7}$ Maisonet and colleagues ${ }^{10}$ reported an increased risk of term low birth weight due to exposure to $\mathrm{CO}$ and $\mathrm{SO}_{2}$ in all trimesters of pregnancy in six cities in North Eastern United States. No effect of exposure to $\mathrm{PM}_{10}$ was noted. ${ }^{10}$ Concentrations of TSP and $\mathrm{SO}_{2}$ in the last trimester of pregnancy were 
associated with low birth weight in four residential areas of Beijing, China. ${ }^{1}$

In a recent study in Poland, Jedrychowski and colleagues ${ }^{17}$ monitored individual exposure to fine particles over 48 hours during the second trimester of pregnancy of 362 women who gave birth between 34 and 43 weeks gestation. $\mathrm{PM}_{2.5}$ exposures in this study averaged $43 \mu \mathrm{g} / \mathrm{m}^{3}$ (with a range of $\left.10-147 \mu \mathrm{g} / \mathrm{m}^{3}\right)$, thus were much higher than those observed in the present study. The authors observed an association between birth weight, birth length, and head circumference, and $\mathrm{PM}_{2.5}$ exposure in the second trimester of pregnancy. A reduction in birth weight at an increased exposure from 10 to $50 \mu \mathrm{g} / \mathrm{m}^{3}$ of 140 grams was estimated.

The hypothesised effect of air pollutants on reproductive health relate to a decreased in utero oxygen supply, resulting from a reduction of oxygen carrying capacity induced by air pollution. ${ }^{4}$ Another possibility is that the production of free radicals induced by air pollution might cause an inflammatory response, increasing blood viscosity. ${ }^{18} 19$ Suboptimal placenta perfusion from blood viscosity changes may cause adverse pregnancy outcomes, including low birth weight and preterm birth. ${ }^{20}$ The possible biological mechanisms involved in the reduction in birth weight associated with maternal exposure to air pollution are likely to vary according to the timing of this exposure. The implantation of the fetus and the formation of the placenta occur during the first trimester, while weight gain occurs predominantly during the third trimester. In the first trimester genetic mutations are generally considered the most important cause of placental abnormalities, and in the second and third trimesters complex vascular alterations are considered to be the main cause of placental abnormalities and consequent fetal growth retardation. ${ }^{21}$ Pollutants are recognised as being able to have an effect on both dimensions. ${ }^{21}$ The effect of air pollutant exposure during pregnancy on birth weight has a plausible biological basis; however, the reported studies fail to show consistency in pollutants and periods during pregnancy where an effect occurs.

The lack of consistency in findings may be due to difficulties distinguishing between pollutants. In this study, when examining multiple pollutant models it appears that $\mathrm{NO}_{2}$ is the most important pollutant, despite the fact that $\mathrm{NO}_{2}$ levels in Sydney are well below the national standard. The lack of consistency in findings among countries may also be accounted for by differences in pollutant levels and mix. Air quality in the Sydney metropolitan area is generally good. Concentrations of pollutants measured at air monitoring sites in Sydney are typically well below standards, although seasonal conditions can cause the occasional exceedence of the national air quality standards. ${ }^{22}$ In Sydney, motor vehicles are a major source of air pollutants, although solid fuel heating for domestic purposes in winter and occasional bush fires in summer also add to the fine particle concentrations. ${ }^{22}$ Given the number of comparisons made in this study, the positive findings may be spurious. It is important, then, to corroborate these finding with future research.

Future research should involve the formation of individual testable hypotheses to avoid the problem of multiple tests. Research should also focus on obtaining higher quality exposure data, for example, modelling air pollution concentrations to smaller geographical areas using emission inventory, traffic density, and meteorological data in the presence of improved time activity data.

In conclusion, we observed that $\mathrm{CO}$ and $\mathrm{NO}_{2}$ concentrations, particularly in the second trimester of pregnancy, have an adverse effect on birth weight. We also observed that $\mathrm{PM}_{2.5}$ and $\mathrm{PM}_{10}$ concentrations in the second trimester of pregnancy have a small adverse effect on birth weight. While the number of studies in this area is accumulating, a

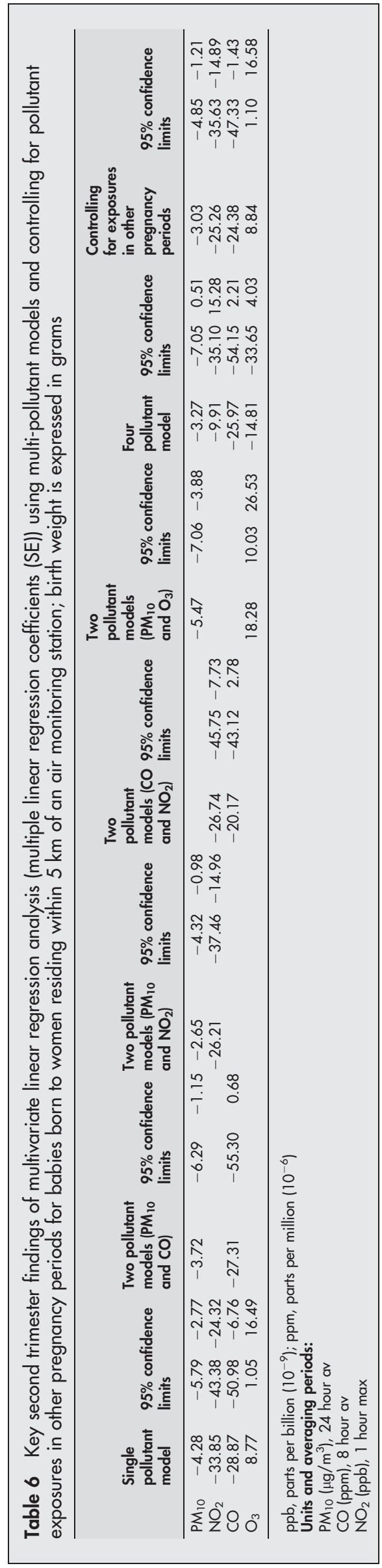


consistent pattern of pollutants and exposure times is not emerging. Further research is required to corroborate our findings.

\section{ACKNOWLEDGEMENTS}

Environmental Health Branch, NSW Health, and Health Research Foundation, South Western Sydney Area Health Service provided funding for this project. Sharyn Lymer assisted with SAS code. NSW Environment Protection Authority and Australian Bureau of Meteorology provided pollutant and meteorological data. The Australian Research Council and collaborators on the ARC SPIRT project "The Assessment of the impact of air pollution on daily mortality and morbidity in Australian cities using a protocol based on international benchmarking" provided valuable assistance with this project.

\section{Authors' affiliations}

T Mannes, NSW Public Health Officer Training Program, New South Wales Health Department, Australia

B Jalaludin, Epidemiology Unit, South Western Sydney Area Health Service, Australia and School of Public Health and Community Medicine, University of New South Wales, Australia

G Morgan, Northern Rivers Department of Rural Health, Sydney

University, Australia

D Lincoln, NSW Biostatistical Officer Training Program, New South

Wales Health Department, Australia

V Sheppeard, S Corbett, Environmental Health Branch, New South

Wales Health Department, Australia

Competing interests: none

\section{REFERENCES}

1 Wang $X$, Ding H, Ryan L, et al. Association between air pollution and low birth weight: a community based study. Environ Health Perspect 1997; 105:105-15.

2 Bobak M. Outdoor air pollution, low birth weight and prematurity. Environ Health Perspect 2000;108:173-6.

3 Dejmek J, Selevan SG, Benes I, et al. Fetal growth and maternal exposure to particulate matter during pregnancy. Environ Health Perspect 1999; 107:475-80.

$4 \mathrm{Ha}$ EH, Hong YC, Lee BE, et al. Is air pollution a risk factor for low birth weight in Seoul? Epidemiology 2001;12:643-8.

5 Bobak M, Richards M, Wadsworth M. Air pollution and birth weight in Britain in 1946. Epidemiology 2001;16:358-9.
6 Gouveia N, Bremner SA, Noveas HMD. Association between ambient air pollution and birth weight in Sao Paulo, Brazil. J Epidemiol Community Health 2004;58:11-17.

7 Ritz B, Yu F. The effect of ambient carbon monoxide on low birth weight among children born in Southern California between 1989 and 1993. Environ Health Perspect 1999; 107:17-25.

8 Rogers JF, Thompson SJ, Addy CL, et al. Association of very low birth weight with exposures to environmental sulfur dioxide and total suspended particulates. Am J Epidemiol 2000;151:602-13.

9 Chen L, Yang W, Jennison BJ, et al. Air pollution and birth weight in Northern Nevada, 1991-1999. Inhal Toxicol 2002;14:141-57.

10 Maisonet M, Bush T, Correa A, et al. Relation between ambient air pollution and low birth weight in the North-Eastern United States. Environ Health Perspect 2001;109(suppl 3):351-6.

11 Liu S, Krewski D, Shi Y, et al. Association between gaseous ambient air pollutants and adverse pregnancy outcomes in Vancouver, Canada. Environ Health Perspect 2003;111:1773-8.

12 Atkinson RW, Anderson HR, Sunyer J, et al. Acute effects of particulate air pollution on respiratory admissions: results from APHEA 2 project. Am J Respir Crit Care Med 2001; 164(10 pt 1):1860-6.

13 Katsouyanni K, Touloumi G, Samoli E, et al. Confounding and effect modification in the short-term effects of ambient particles on total mortality: results from 29 European cities within the APHEA2 project. Epidemiology $2001 ; 12: 521-31$

14 Le Tertre A, Medina S, Samoli E, et al. Short-term effects of particulate air pollution on cardiovascular diseases in eight European cities. J Epidemiol Community Health 2002;56:773-9.

15 Roberts CL, Lancaster PAL. Australian national birth weight percentiles by gestational age. Med J Aust 1999;170:114-18.

16 Glinianaia SV, Rankin J, Bell R, et al. Particulate air pollution and fetal health: a systematic review of the epidemiologic evidence. Epidemiology 2004; 15:36-45.

17 Jedrychowski W, Bendkowska I, Flak E, et al. Estimated risk for altered fetal growth resulting from exposure to fine particles during pregnancy: an epidemiologic prospective cohort study in Poland. Environ Health Perspect 2004; 112:1398-402.

18 Peters A, Doering A, Wichmann HE, et al. Increased plasma viscosity during an air pollution episode: a link to mortality. Lancet 1997;349:1582-7.

19 Bouthillier L, Vincent R, Goegan P, et al. Acute effects of inhaled urban particles and ozone: lung morphology, macrophage activity, and plasma enothelin-1. Am J Pathol 1998;153:1873-84.

20 Knottnerus JA, Delgado LR, Knipschild PG, et al. Haematologic parameters and pregnancy outcome: a prospective cohort study in the third trimester. $J$ Clin Epidemiol 1990;43:461-6.

21 Lin CC, Santolaya-Forgas J. Current concepts of fetal growth restriction: Part 1: Causes, classification and pathophysiology. Obstet Gynaecol 1998;92:1044-55.

22 New South Wales Environment Protection Authority. State of the environment 2000. Sydney: NSW Environment Protection Authority, December 2000, Available: http://www.epa.nsw.gov.au/index.htm [accessed July, 2003]. 